\title{
MODELANDO A VIDA NO CÓRREGO DE AREIA: TRADIÇÃO, SABERES E ITINERÁRIOS DAS LOUCEIRAS
}

\author{
Francisca R. N. Mendes ${ }^{1}$
}

\section{Introdução}

As sociedades contemporâneas são marcadas por diferentes modos de produção, trabalho e sociabilidade, inseridos no âmbito das economias globalizadas. Contudo, o tecido social de vários contextos históricos é também constituído por sistemas simbólicos, que promovem o intercruzamento de saberes tradicionais e modernos. Nesse sentido, o artesanato pode ser pensado como um lugar privilegiado para se entender uma determinada coletividade, uma vez que materializa experiências vividas no cotidiano de muitas localidades.

No Ceará, ele é uma considerável fonte de renda para muitas famílias ${ }^{2}$ e sinônimo de variedade de tipologias. Do bordado aos objetos feitos de barro, passando pelo couro, trançados de palha, madeira, labirinto, rendas e xilogravura, os saberes, fazeres, significados e vivências são transmitidos de geração a geração. No dia-a-dia, tais peças podem adquirir funções utilitárias, decorativas, lúdicas ou religiosas.

Fazer louça de barro não é uma atividade que possa ser entendida apenas do ponto de vista comercial. Um olhar mais atento sobre o cotidiano da produção revela as visões de mundo, o imaginário, os arranjos sociais, enfim, a arte de quem a faz. Enquanto modelam seus objetos, os artesãos moldam as próprias vidas, numa constante criação e recriação de seu universo cultural particular.

O objeto de estudo desse trabalho é a teia de relações sociais constituinte da produção artesanal de louça de barro do Córrego de Areia, localidade no município de Limoeiro do Norte/CE. A interação das louceiras com instituições como a Central de Artesanato do Ceará (CEART), além das feiras e dos compradores avulsos vai revelar os vínculos que elas têm com os poderes socialmente estabelecidos, oficiais, mas principalmente aponta para as polifonias existentes no interior do próprio lugar.

Assim, creio que a produção artesanal só pode ser entendida se a consideramos como um palco de pelejas pelos recursos públicos, por bens materiais e, sobretudo,

\footnotetext{
${ }^{1}$ Universidade Federal do Ceará, Brasil.

${ }^{2}$ O Sindicato dos Artesãos do Estado do Ceará estima que cerca de cem mil pessoas sobrevivam da produção de itens artesanais no Estado. Só na CEART, ligada à Secretaria do Trabalho e Desenvolvimento Social (STDS), são 42.963 profissionais cadastrados (Dados de 2012).
} 
pelos bens simbólicos, caracterizando assim uma luta pelo poder, expressa no desenrolar do próprio cotidiano das louceiras.

As mulheres dominam todas as etapas da produção, desde a retirada do barro do barreiro até a queima, parte final do processo de feitura de louça. ${ }^{3}$ A venda é feita de forma individual e cabe aos homens apenas a construção dos fornos, salvo alguns poucos que ainda fazem louça, mas em número pouco expressivo. A memória das louceiras revela, entretanto, que o artesanato já foi ocupação também, no passado, dos homens do Córrego de Areia, em virtude da grande saída que os objetos de barro tinham, a mão-de-obra masculina era utilizada de forma equivalente à feminina.

Hoje, os homens têm outras ocupações, pois estão na agricultura, na pecuária, são pedreiros ou moto-taxistas. Doze famílias - que apresentam sempre algum grau de parentesco - ainda vivem da produção de louça e apenas dois homens estão envolvidos na modelagem, sendo que um deles não participa do acabamento das peças.

Para ter acesso a tais vivências, apropriar-se das memórias e narrativas das louceiras foi imprescindível. Partindo das trajetórias particulares, pude perceber como o saber artesanal é transmitido de uma geração a outra, levando em conta as referências do passado. Desse modo, as redes de sociabilidade e de circulação das peças produzidas no Córrego vão sendo constituídas e reconstituídas com o passar dos anos. Afinal, conforme lembra Ecléa Bosi (1994) "Lembrar não é reviver, mas refazer, reconstruir, repensar, com imagens e idéias de hoje, as experiências do passado".

Os dados apresentados nesse trabalho foram inicialmente expostos em forma de tese de doutoramento, intitulado A Louça de Barro do Córrego de Areia: tradição, saberes e itinerários, defendida na Universidade Federal do Ceará, em junho de 2009. Tais dados são frutos de mais algumas idas e vindas à localidade, iniciadas em junho, e tendo continuidade no segundo semestre de 2006, além dos meses de maio a julho de 2007 e, por fim, de maio a setembro de 2008, quando eu segui semanalmente as louceiras, no desenrolar do seu dia-a-dia, nos afazeres domésticos, nas retiradas do barro e queima da louça, nas idas à casa de irmãos, à feira ou à bodega ${ }^{4}$, enquanto buscavam as crianças na escola ou modelavam algumas peças. Aproveitava esse

\footnotetext{
${ }^{3}$ As louceiras chamam os objetos que fazem de loiça.

${ }^{4} \mathrm{Na}$ zona rural e nas cidades do interior e do litoral nordestino, é comum essa denominação para pequenas vendas ou mercearias onde se encontra uma infinidade de produtos, desde mantimentos até remédios para pessoas e animais.
} 
convívio para conversar a respeito de vários assuntos ${ }^{5}$ - umas vezes gravava, em outras anotava - afinal, tais mulheres não são apenas louceiras, são também mães, esposas e donas de casa.

Acompanhei ainda, as várias etapas do fazer, de várias artesãs e mediante a observação das fotografias tiradas nesses momentos pude ter uma compreensão mais ampla das ações e gestos empreendidos. Para Mattos (2001), os registros fotográficos permitem o prolongamento do contato com a realidade, após o trabalho de campo.

\section{Córrego de Areia - geografia das sociabilidades}

O município de Limoeiro do Norte está situado no vale do Jaguaribe, mais precisamente na região do baixo rio Jaguaribe ${ }^{6}$. O Córrego de Areia é um dos muitos acidentes geográficos escavados pelo rio Jaguaribe na grande enchente ocorrida no inverno de 1886. A abundância de água e a fertilidade do solo favoreceram a fixação das pessoas por lá, que posteriormente vieram a desenvolver a habilidade de produzir utensílios de barro. Chega-se lá percorrendo quase sete quilômetros pela CE 358, rodovia que durante muitos anos serviu de ligação entre as cidades de Limoeiro do Norte e Tabuleiro do Norte, mas era um caminho alternativo, sem asfalto e o tráfego de veículos ficava interrompido no período chuvoso em razão do aumento no volume de água do rio Jaguaribe, que divide os dois municípios. As motos, bicicletas e pedestres faziam a travessia de canoa.

A atividade artesanal no Ceará é um meio de sobrevivência antigo e bastante diferenciado, ligado à agricultura de subsistência (Porto Alegre, 1994). Portanto, é necessário entendermos primeiro o processo histórico das relações sociais no campo para depois partirmos para o entendimento do artesanato, inserido nesse contexto. $\mathrm{O}$ algodão e a pecuária foram responsáveis pela geração de uma indústria artesanal e doméstica, que adquiriu importância significativa na economia cearense em meados do século passado.

\footnotetext{
5 As entrevistas realizadas eram semiestruturadas, possibilitando ser flexível, deixando que as pessoas falassem a respeito do assunto que lhes conviesse, ao mesmo tempo em que esclareciam aspectos sobre o trabalho e as relações sociais que ainda não estavam claros para mim.

${ }^{6}$ A bacia do rio Jaguaribe abrange 55\% do território do Estado, correspondendo a 80 municípios que ocupam $80.547 \mathrm{~km} 2$. Cerca de $29.7 \%$ da população estadual reside na bacia do rio Jaguaribe. A bacia do rio Jaguaribe foi subdividida em cinco sub-bacias pelo Plano Estadual de Recursos Hídricos (1992): Alto, Médio e Baixo Jaguaribe, sub-bacia do rio Banabuiú e sub-bacia do rio Salgado. A cidade de Limoeiro do Norte fica a $204 \mathrm{~km}$ da capital, Fortaleza.
} 
No artesanato produzido no Córrego de Areia, cuja origem já se perdeu com o tempo, identifica-se, com base na memória das louceiras, a ligação deste com a agricultura, quando elas dizem que, no passado, o trabalho artesanal em louça era feito concomitante ao plantio para subsistência, que algumas vezes também podia ser vendido.

Todo mundo trabalhava na roça e na loiça. [...] Quando nós chegava da roça, dez hora, dez e meia, aí pisava o barro, começa duas vasilha, aí ia pro colégio. Já era mocinha de dez, doze anos. Aí quando chegava da escola, quatro e meia, cinco horas, aí trabalhava até dez hora da noite, toda noite. Num era muita loiça, o tempo era pouco, devido a roça, trabaiava na roça, o tempo era pouco pra loiça. [...] $\mathrm{O}$ algodão, o algodão era vendido, mas o feijão e o milho era pra nós mermo. (Antônia Ribeiro, maio de 2007)

Ia tudim plantar feijão, milho, aí quando terminava de colher esses da, começa no algodão. Ia papai, mamãe, Bibia, Mundinha, Terezinha, era seis filha, ia cinco e ficava uma pra cozinhar o comer. Ia tudo, aí quando chegava tudo ia cuidar no barro. Fazia tudo, pote, quartinha, panela, alguidar, tudo tudo. (Antônia Ribeiro, julho de 2008)

A meu ver, as mudanças que ocorreram no contexto socioeconômico do município, apresentadas anteriormente, que têm a substituição da agricultura de subsistência pelo trabalho assalariado como principal exemplo, levaram à migração da mão-de-obra masculina do artesanato para os plantios de arroz e feijão. Levantei esta hipótese com suporte nas falas das louceiras, quando elas rememoram o tempo em que a única ocupação dos homens e mulheres do Córrego de Areia era fazer louça de barro, alvitrando, também a saída dos homens dessa atividade. A introdução da rizicultura alterou, de modo sem precedentes, as relações sociais da produção artesanal, ao ponto de, até os dias atuais, a maioria dos maridos das louceiras terem a agricultura como atividade principal, seja cuidando de um pedaço de terra do qual é proprietário ou trabalhando sob o regime de salário nos grandes plantios locais. Desde então, a louça passou a ser uma ocupação essencialmente feminina. "Teve deles que foi porque morreu, teve deles que arrumou outro serviço". (Antônia Ribeiro, maio de 2007)

Todo mundo fazia loiça e a mãe de mãe também trabalhava. Nesse tempo ai o pessoal vivia só da loiça, todo mundo trabaiava muito, homens e mulher, era todos. Aí o pessoal foi crescendo e foi arranjando outros emprego e foram deixando de mão. (Lúcia Rodrigues, agosto de 2008)

Segundo as narrativas das pessoas mais idosas do lugar e das próprias louceiras, a atividade artesanal foi iniciada por quatro irmãs, chamadas de Mercês, em homenagem ao pai, que era conhecido por Chico de Mercê, e teria morrido, por volta do fim do 
século $\mathrm{XIX}^{7}$. No dia-a-dia, as louceiras usam o termo arte como designador de sua profissão, sua forma de sobreviver, pois não há separação entre trabalho e modo de vida. "Essa arte tendo quem compre é muito boa". (Tereza Rodrigues, julho/2002). "Minha arte de pequeno era fazer cavalim" [cavalinho]. (Zé Pequeno apud Revista Interior, 1984).

Assim como acontece em outros lugares, descritos por Bezerra (2007), Porto Alegre (1994) e Lopes (1978), para as louceiras do Córrego de Areia, essa ligação entre trabalho/sustento e vida cotidiana é inseparável. O modo de viver e a produção artesanal estão totalmente imbricados, por isso é comum, também, se referirem à produção artesanal como trabalho. Portanto, arte e trabalho, para essas mulheres, são sinônimos. "Quem trabaia [trabalha] nisso aqui passa o dia todim agarrado". (Raimunda Ribeiro, maio de 2007). "No tempo de meu pai, eu trabaiava [trabalhava] mais ele. Comecemo [Começamos] a trabaiar [trabalhar] em casa, vendendo pra aqui, pra acolá”. (Maria Rodriques, julho de 2008)

As louceiras estão situadas geograficamente no mesmo espaço, mas isso não significa dizer que elas partilham os mesmos gostos, crenças e sentimentos de pertença (Bailey, 1971; Sayad, 2001; Redfield, 1965). Trabalhando de forma separada, cada uma na sua casa, não constituem uma unidade de identidade, não se reconhecem como um grupo.O espaço físico é delineado de acordo com as relações e competições estabelecidas socialmente, o que nos permite perceber o Córrego de Areia como lugar permeado por conflitos, que vêm à tona em determinados momentos, revelando disputas entre as louceiras, muitas vezes muito maiores do que qualquer fronteira física. Em outras palavras, morar no mesmo local e realizar o mesmo tipo de atividade não significa a inexistência de embates (Bourdieu, 2001). As louceiras disputam desde o local para retirar o barro do barreiro até os compradores, passando pelo melhor ponto na feira, o status e o mercado.

Apesar de a produção e a venda do artesanato serem realizados, na maioria dos casos, de forma individual, há alguns "núcleos familiares" ${ }^{8}$ " bem definidos e coesos, que herdaram um "status" do saber artesanal - em razão da fama alcançada por algum parente - que lhes possibilitou ampliar seu mercado e alcançar, por exemplo, a Central de Artesanato do Ceará (CEART), em Fortaleza. O conflito é latente entre as famílias

\footnotetext{
${ }^{7}$ Cheguei a essa provável data baseada nas referências que as louceiras fazem aos seus antepassados que já faziam louça. Creio que essa seja a terceira ou quarta geração de louceiras, pelo que as pessoas mais idosas do lugar conseguem relembrar.

${ }^{8}$ Expressão utilizada por Porto Alegre (1994).
} 
Braúna e Pequeno, únicas do lugar a venderem para tal instituição e se revela quando as louceiras, de ambos os lados, reivindicam para si o pioneirismo na venda para a CEART.

Há também, no entanto, outras louceiras que, apesar de não estarem tão fechadas em suas famílias nucleares, se agrupam no compartilhamento de outros interesses: vão às feiras para vender suas peças e há relações de compadrio, vizinhança ou parentesco de segundo e terceiro graus. Elas, entretanto, também disputam compradores e buscam o reconhecimento do seu trabalho, quando verbalizam as especificidades da sua produção ou a originalidade das suas peças.

Cada louceira tem sua "especialidade". Umas fazem potes, quartinhas, alguidares, chaminés, filtros, cavalos, cofres, bebedouros para galinha, que se diferenciam em tamanho, formatos, espessura ou pela utilização do tauá, ao qual elas chamam de toá. Algumas louceiras utilizam essa tintura, que pode ser vermelha ou branca, obtida por meio do barro das duas tonalidades; o vermelho é abundante na região, mas o branco só é encontrado a muitos quilômetros de distância no município de Tabuleiro do Norte, na chapada do Apodi. A tradição de pintar as peças vem das gerações anteriores. Dentre os que me foram relatados, Zé Pequeno era um dos artesãos que mais utilizava essa técnica, quando pintava os caçuás ${ }^{9}$ dos animais que fazia. Conforme relembra Maria, sua filha, os cavalo de papai era tudo pintado.

Outras modelam jogos de feijoada, travessas, cinzeiros, jarros, petisqueiras, luminárias, que têm características próprias, ou, no dizer delas, cada qual faz uma qualidade de coisa. Nenhuma peça é igual à outra e mesmo aquelas que repetem a tipologia sempre imprimem algum detalhe que garante a unicidade do objeto: "a loiça de Maria é diferente da de Lúcia, a minha é diferente da de Maria e da de Lúcia" (Raimunda Ribeiro, maio de 2003).

A louça de barro, no entanto, não é composta apenas de uma dimensão concreta, palpável. Nela estão embutidas várias relações pessoais, familiares, sociais, econômicas e simbólicas que só podem ser percebidas em um mergulho no cotidiano do Córrego de Areia. Para quem observa de fora, tais minúcias podem passar despercebidas e elas é que regem as teias sociais onde as louceiras e a louça se prendem (Geertz, 1978).

\footnotetext{
${ }^{9}$ Trata-se de um cesto grande, que pode ser feito de cipós, talo de carnaúba ou couro, com hastes pelas quais se prende às cangalhas, transportadas principalmente pelos jumentos.
} 


\section{Dimensões Simbólicas da Louça}

Nesse conjunto de relações que compõem o universo econômico, político, social e cultural do trabalho artesanal das louceiras, não podemos desconsiderar o emaranhado de teias sociais que constituem o seu sistema simbólico (Geertz, 1989). Por meio da observação de comportamentos, gestos, atitudes e falas dessas mulheres, quando elas se referem ou realizam a sua arte, tentei alcançar a visão do mundo e o valor dos símbolos presentes no cotidiano do trabalho.

Para um artesão, o valor simbólico está na relação estabelecida entre ele e o barro durante toda a produção das suas peças. Para Xavier (2001: 12), "vencer o barro é vencer as intempéries da vida”. É nessa luta constante pela sua sobrevivência, ao moldar, pintar ou queimar o barro, que são deixados nas peças os valores e sentimentos de quem as produziu.

Herança cultural dos antepassados, essa arte passou por mudanças e adotou outros estilos. Atualmente, os objetos de barro estão sendo valorizados e admirados com base apenas em outros critérios estéticos, mediados pelos consumidores, diferentes daqueles funcionais ou utilitários em meio dos quais foram produzidas, cuja estética obedecia às categorias nativas. Logo, quando postos num âmbito diferente e mais amplo, tais exemplares adquirem outro significado, ou seja, são reelaborados, refuncionalizados, conforme aponta Canclini (1993).

À medida que os potes, panelas, enfeites, pratos de barro vão sendo substituídos por produtos industriais, é criado um "entrelaçamento de sistemas simbólicos", ou seja, é possível encontrar utensílios de plástico e alumínio nas moradias da zona rural e objetos e adornos feitos de barro em apartamentos, casas e lojas, nos mais variados centros urbanos do país (Mattos, 2001). Para explicar a ausência desses utilitários, a autora aponta o status produzido pelas peças de plástico e alumínio, que, ao serem investidas do simbolismo da modernidade, acabaram suprindo necessidades antes ocupadas pelos utensílios de barro.

Talvez por isso tenham tão pouco valor de mercado, uma vez que têm o seu caráter funcional facilmente substituído. Em contrapartida, os objetos de adorno alcançam um preço muito mais alto nesse mesmo mercado, porque os compradores entendem que dão mais trabalho para fazer, e são admirados pela estética e, muitas vezes, considerados trabalhos artísticos. Portanto, quando percebemos a diversificação 
de funções socioculturais da arte do barro, atingimos as estratégias sociais que envolvem a sua utilização. É possível ver, ainda, como o significado antigo de um objeto utilitário ou ornamental pode ser ultrapassado e, dependendo do contexto, um novo sentido pode ser criado.

Ao contrário da arte erudita, que prima pela originalidade da obra e do artista, quem realiza uma prática artesanal não está interessado em ser único nem diferente, mas sim em conseguir expressar seu pensamento por meio de um trabalho manual. Nesse processo, muitos assumem o "status de artista", por se verem como realizadores de um trabalho admirado pela sua qualidade, beleza e complexidade (Porto Alegre, 1994). Para as louceiras do Córrego de Areia, a busca pela perfeição é freqüente, porque é a preocupação com os detalhes, com o acabamento, que vai definir a sua "marca", fazendo com que a peça seja reconhecida por ela, pelas outras louceiras e pelos compradores que conhecem sua arte.

\footnotetext{
Quanto mais lisa, o quanto eu puder pelejar para ficar mais bonita, eu pelejo, aonde eu vir eu conheço que é minha e conheço das outra também. Tem gente que chega aqui procurando aquelas panela fininha, alisadinha, que só eu tenho paciência de alisar (Maria Rodrigues, abril de 1998) ${ }^{10}$.
}

Geertz (1989) entende que a interpretação antropológica é centrada no significado que instituições, ações, imagens, formas de expressão, eventos, costumes têm para os seus agentes. Mergulhando no universo de suas significações, é que busco encontrar os significados que o trabalho artesanal tem para as louceiras do Córrego de Areia. Nesse sentido, Sahllins (1987) entende a cultura como algo construído, produzido com base na ação. Ela é responsável pelo processo histórico de "significação das coisas", ou seja, pelos diferentes sentidos atribuídos por um determinado grupo às suas várias manifestações, materiais e imateriais.

No Córrego de Areia, pude identificar a existência de dois discursos, que encontram ressonância no tipo de peça produzida e no mercado que a absorve. Algumas louceiras dizem que só realizam o trabalho com o barro por falta de opção, por não haver outra forma de ocupação, nem como garantir o sustento da família. Essas louceiras são algumas daquelas que têm, em sua maioria, o artesanato como única fonte de renda. Vendem nas feiras da região ou para atravessadores e fazem, quase sempre, apenas a louça utilitária que, conforme mencionado, é vendida nas feiras e tem menos

\footnotetext{
${ }^{10}$ MENDES, Francisca R. N. Remodelando Tradições: os processos criativos e os significados do trabalho artesanal entre as louceiras do Córrego de Areia. Dissertação. Programa de Pós-Graduação em Sociologia. Universidade Federal do Ceará-UFC. Fortaleza-CE, 2004.
} 
"saída". Queixam-se ainda, do esforço físico despendido durante a produção, para, segundo elas, obter pouco retorno financeiro e não haver garantia de que vai ter quem compre. Apontam, ainda, que não veem interferências que possibilitem um aumento nas vendas e compensem a realização do trabalho, que, de acordo com algumas louceiras, não dá sustento a ninguém:

É uma vida corrida porque todo serviço tem um futuro, esse não. Porque quando você é empregado, com vinte e cinco anos, trinta de serviço, você ta esperando já uma coisa melhor, um aposento, uma coisa melhor, essa não tem não. Porque nunca foi divulgado, nunca teve valor essa arte né?

(Maria Eunice Freitas, maio de 2007)

“Eu não gosto não, só trabaio porque é o jeito, tem dia que eu digo que qdo eu terminar essa encomenda, não vou mais trabaiá nisso não". (Maria Acelina, maio de 2007).

$\mathrm{Na}$ tentativa de compreender tais posicionamentos, é necessário nos remeter ao processo histórico de industrialização que faz com que a louça utilitária não tenha mais a mesma "saída" da louça figurativa, em virtude, principalmente, da existência de objetos similares e até mais baratos como os utensílios de plástico e alumínio, que possuem grande durabilidade e são de fácil manuseio e substituição.

A segunda questão refere-se ao requinte estético de tais peças (Mattos, 2001: 112). As peças utilitárias "são bonitas, não a despeito de, mas graças a sua utilidade", pois esses objetos trazem consigo a marca, os sinais, as histórias dos artistas e do lugar onde foram produzidos, ressaltando as diversas particularidades e peculiaridades que enriquecem o artesanato. Apesar da sua beleza e funcionalidade, na produção de louça utilitária, elementos como o tempo despendido, a dificuldade de realizar o trabalho, o acabamento, a complexidade do objeto, enfim, a estética, são menos percebidos e valorizados pelos possíveis consumidores.

Dias (2006: 67) mostra que as panelas, por exemplo, só são de barro durante a sua produção, mas após a queima são convertidos em objetos de cerâmica, "um produto cerâmico, cuja matéria-prima é a argila, submetida a um processo de transformação físico-químico através do fogo".

As louceiras lançam mão de temporalidades diferentes, quando trazem para o presente uma memória da infância ou adolescência, em que viviam exclusivamente da louça, que, segundo elas, era uma atividade bastante rentável. 
Antigamente, a gente vivia só mermo do dinheiro do loiça, quando era pra levar pra feira, todo sábado, levava e vendia tudo e tinha muitas vez que ainda vinham procurar mais e ainda num tinha. Tinha vez que vinha muita gente de fora, um homem de Fortaleza comprava. A venda era muito boa, ave maria, a gente vivia só da venda dessa loiça. Agora não vende mais nada. (Ercília Braúna, agosto de 2008)

Ultrapassando a sua constituição material, o que está posto na louça de barro é um acervo social historicamente produzido, que, no caso do Córrego de Areia é ignorado pelo poder público, seja ele municipal, estadual ou federal, que nunca desenvolveram ações que considerassem esse legado e pudessem implementar alguma melhoria nas condições de produção ou de vendas. Também são comuns as queixas sobre o baixo valor da louça e o discurso recorrente de que, se houvessem mais compradores, elas teriam "gosto" em fazer. "A arte tá desvalorizada. Mas acho que o povo também num conhece não, se tivesse saída eu fazia”. (Antônia Ribeiro, julho de 2008)

Falta interesse das pessoas, divulgação, não só por aqui, em vários lugar. Porque aqui ninguém valoriza. A gente vê na televisão que tem coisa bem mais simples do que a gente faz que vende e aqui não tem quem compre. (Carmelita Ribeiro, julho e 2008)

Desse modo, quando mencionam não gostar e só modelar as peças por falta de outra opção, essas louceiras estão, na verdade, se referindo aos aspectos apresentados há pouco como os principais responsáveis pela falta de mercado para a louça utilitária, à desvalorização da sua arte e à falta de incentivos para a sua manutenção. Não se pode entender tal sentido observando apenas o lado econômico, pois, se fosse só pelo sustento, essas mesmas mulheres poderiam largar o barro e ir trabalhar na agricultura ou realizar serviços gerais, comuns na região, como lavar roupa ou trabalhar em casa de família.

Elas mudam, entretanto, o tom de voz e têm os olhos brilhando quando enfatizam que "vivem do barro". Em outras palavras, sentem-se orgulhosas de retirar dele o sustento de toda a família, além do prazer e satisfação em produzir objetos com as próprias mãos; afinal, é essa arte que vem dos seus pais e avós que lhes permite oferecer aos filhos, por exemplo, o acesso a alguns bens materiais e simbólicos, conforme aponta Raimunda: "compro as coisa pros meus filho, sustento tudim, de estudo, do dinheiro do meu barro".

Nesse sentido, pude perceber entre as louceiras o despertar de sentimentos como vaidade e orgulho de si mesmas, reconhecimento e admiração, quando se referem à sua produção, de forma tão pulsante, que não lhes permite sequer mencionar as dificuldades 
encontradas no dia-a-dia do trabalho ou as poucas vantagens financeiras. É nesse sentido que Porto Alegre (1994) ressalta a inserção de aspectos como habilidade e criatividade do artista, no domínio de sua arte, fundamentais para que ele se reconheça como tal. Daí, serem tão importantes aspectos como a perfeição, a durabilidade, a qualidade, enfim, as avaliações que fazem a "fama" de um artista e lhe trazem sentimentos de dignidade e orgulho.

As louceiras que manifestam tais sentimentos são principalmente aquelas que fazem objetos de adorno, procurados apenas pela sua estética, a louça de modelo, como é chamada por elas. Vendem para a CEART, sob encomenda, ou nas feiras, mas o que as diferencia é exatamente o repertório de peças não utilitárias. A vaidade e o sentimento de artista são facilmente percebidos, pois elas verbalizam o prazer que têm em ser louceira e o orgulho de si mesmas e do que fazem. Na fala de Ercília Braúna: "Ave Maria, eu gosto, eu adoro mermo ser loiceira. Gosto demais". Mesmo enfrentando dificuldades financeiras, estas e a luta pela sobrevivência são elementos constituintes do cotidiano dessas pessoas, mas não se pode vê-los como fatores determinantes para o processo de criação, composto pelo novo, pelo imponderável, pelo improviso, enfim, pelas "idéias na cabeça".

Portanto, a valorização da louça de modelo, e, consequentemente, do trabalho artesanal de algumas louceiras, no Córrego de Areia, aconteceu com a entrada da CEART na localidade, que tem como marco, de acordo com as informações obtidas na instituição e pelas louceiras, o início dos anos 1990. Como quem faz esse tipo de peça tem para onde vender e suas criações são admiradas e julgadas como sendo mais difíceis de fazer, a produção está toda voltada para um circuito turístico, onde os sentidos atribuídos ao próprio trabalho se diferenciam daquele despertado em quem faz apenas louça utilitária. Aqui, os valores colocados - pela CEART, pelos compradores e pelos media - são, sobretudo, ligados à beleza, à delicadeza, à leveza, produzindo um status e um discurso de artista que é absorvido pelas louceiras, que não encontram dificuldades para escoar aquilo que produzem.

A loiça que eu tiver pronta, quem chegar compra e de vez em quando aparece gente eu vendo. A Ceart é doidinha pela minha loiça, é só em que fala, já vinhero aqui umas três vez mode eu fazer, já mandaro num sei quantos recado pra mim. (Maria Rodrigues, agosto de 2008) 
Parece dimensão do valor artístico, do fazer arte, do criar e do prazer em fazer as peças, que compõe o imaginário, o simbolismo e o sentido do trabalho artesanal, no cotidiano das louceiras do Córrego de Areia. Segundo Porto Alegre (1994), o artista sente orgulho do seu trabalho porque é por intermédio dele que a autonomia é conquistada. Também é comum para essas pessoas trabalharem mesmo com a idade avançada, pois vivem por conta própria e gostam do que fazem. Desse modo, há louceiras no Córrego de Areia que não conseguem ficar sem "trabalhar" e não abandonam a tradição, senão adoecem, como nos casos de Dona Terezinha e Maria de Zé Pequeno:

Eu já tirei uma semana de férias, disse vou passar uma semana sem trabaiar em loiça, vou ajeitar minha casa que a minha casa é que nem um chiqueiro de porco. Aí vai eu tiro uma semana pra ajeitar as coisas, mas não dá, eu fico doente. (Maria Rodrigues, agosto de 2008)

Esse processo de atribuir significados culturais a objetos de arte é sempre local, afinal, o sentimento despertado pela arte está contido numa totalidade maior composta por elementos como religião, ciência, comércio, lazer e política que regulam e organizam a vida prática do indivíduo (Geertz,1997).

Portanto, quando as louceiras falam do seu cotidiano, de como realizam suas tarefas domésticas, de suas relações com o marido e os filhos, dos sentimentos que o trabalho artesanal desperta, elas estão falando também de arte, mais especificamente, da sua arte, sendo impossível separar trabalho e modo de viver. Ao fazerem peças de barro, estão materializando a sua forma única de viver, naquele lugar e naquele momento histórico.

A experiência de vida é concretizada em detalhes, e se entendemos o que essas pessoas pensam, falam e fazem a respeito do seu próprio trabalho, alcançaremos o sentido, o significado que ele pode ter, para elas próprias. É o que Geertz (1997: 111) exprime quando diz que está buscando alcançar o entendimento do "senso comum", ou seja, o ponto de vista do nativo. Logo, poderíamos dizer que ser louceira é, ao mesmo tempo, ser artista e trabalhadora.

As duas categorias se confundem e se misturam, na maioria dos casos, não sendo do meu interesse aprisioná-las em classificações estanques e imutáveis. 


\section{Considerações Finais}

$\mathrm{Na}$ perspectiva de alcançar a rede de relações sociais que constitui a produção artesanal de louça de barro do Córrego de Areia, localidade no município de Limoeiro do Norte, CE, foi possível perceber que a interação das louceiras com diferentes sociabilidades. Mesmo com a produção e a venda do artesanato sendo realizadas, na maioria dos casos, de forma individual, há alguns núcleos familiares bem definidos e coesos, que herdaram um status do saber artesanal - em razão da fama alcançada por algum parente - que lhes possibilitou ampliar seu mercado e alcançar, por exemplo, a Central de Artesanato do Ceará (CEART), em Fortaleza. O conflito é mais sensível entre as famílias Braúna e Pequeno, somente as que, no lugar, vendem para tal Instituição, e se revela quando as louceiras, de ambos os lados, reivindicam para si o pioneirismo na venda para a CEART. Tais embates foram reforçados com a promoção de Lúcia Pequena à Mestre da Cultura Popular Tradicional, pelo Governo do Estado, em 2004, título concedido sem a legitimidade das outras louceiras.

Cada louceira tem a sua "especialidade". Umas fazem potes, quartinhas, alguidares, chaminés, filtros, cavalos, cofres, bebedouros para galinha, que se diferenciam em tamanho, formatos, espessura ou pela utilização do tauá. Outras modelam jogos de feijoada, travessas, cinzeiros, jarros, petisqueiras, luminárias, que têm características próprias, ou, no dizer das louceiras "cada qual faz uma qualidade de coisa”. Nenhuma peça é igual à outra e mesmo aquelas que repetem a tipologia sempre imprimem algum detalhe que garante a unicidade do objeto.

A louça de barro, no entanto, não é composta apenas de uma dimensão concreta. Nela estão embutidas várias relações pessoais, familiares, sociais, econômicas e simbólicas que só podem ser percebidas com um mergulho no cotidiano do Córrego de Areia. Para quem observa de fora, tais minúcias podem passar despercebidas e são elas que regem as "teias sociais" onde as louceiras e a louça se prendem. A transmissão do saber e as relações de gênero, assim como as dimensões simbólicas que as louceiras atribuem a si e à louça, contribuem para a constituição da identidade louceira, que é entremeada por valores como zelo, afinco e esmero na produção das peças.

Convém ressaltar, contudo, que apesar de serem conhecidas dentro e fora do Córrego de Areia como "as louceiras", essas mulheres não podem ser pensadas como uma categoria só, que denote unidade, pois têm histórias de vida, visões de mundo e interesses diversos, que as impedem de estabelecer identidade única. 


\section{Referência}

AlviM, Maria Rosilene Barbosa. Artesanato, tradição e mudança social: um estudo a partir da "arte do ouro" em Juazeiro do Norte. In O artesão tradicional e seu papel na sociedade contemporânea. Textos de Berta G. Ribeiro e outros. Rio de Janeiro, FUNARTE/ Instituto Nacional do Folclore. 1983. 253p.

Bailey, F.G. Gifts e Poison. In Gifts e Poison. Oxford: Basil Blackwell, 1971, pp 125.

BosI, Ecléa. Memória e Sociedade: lembranças de velhos. $3^{\text {a }}$ ed. - São Paulo-SP: companhia das letras, 1994.

Bourdieu. Efeitos de Lugar. In A Miséria do Mundo. Petrópolis, Vozes, 2001, pp 159-166.

CANCLINI, Nestor García. Culturas Híbridas: estratégias para entrar e sair da modernidade. $4^{\text {a }}$ edição, São Paulo: Editora da Universidade de São Paulo, 2003 (Ensaios Latino-americanos).

As Culturas Populares no Capitalismo. Campinas:

Papirus, 1993.

Carvalho, Gilmar de. Artes da Tradição: mestres do povo. Fortaleza: Expressão Gráfica / Laboratório de Estudos da Oralidade UFC/UECE, 2003.

DiAS, Carla. Panela de Barro Preta: a tradição das Paneleiras de Goiabeiras - VitóriaES. Rio de Janeiro: Mauad X: Facitec, 2006.

GeERTZ, Clifford. Centros, Reinos e Carismas: reflexões sobre a simbologia do poder. In Saber Local: novos ensaios em antropologia interpretativa. Tradução de Vera Mello Joscelyne. Petrópolis-RJ: Vozes, 1997.

A Interpretação das Culturas. Rio de Janeiro: Guanabara Koogan: 1978.

Hertz, Robert. A Preeminência da Mão Direita: um estudo sobre a polaridade religiosa. In Religião e Sociedade, n.06, 1980, pp 99-128.

LIMA, Ricardo Gomes. O Povo do Candeal: sentidos e percursos da louça de barro. Tese (Doutorado em Antropologia Cultural). Programa de pós-Graduaçao em Sociologia e Antropologia. UFRJ, IFCS. Rio de Janeiro: 2006.

LOPES, José Sérgio Leite. Vapor do Diabo: o trabalho dos operários do açúcar. Rio de Janeiro: Paz e Terra, $2^{a}$ ed., 1978. (Estudos Brasileiros, v. 10) 
Mattos, Sônia Missagia. Artefatos de Gênero na Arte do Barro (Jequitinhonha). Vitória: Edufes, 2001.

MEndes, Francisca R. N. Remodelando Tradições: os processos criativos e os significados do trabalho artesanal entre as louceiras do Córrego de Areia. Dissertação de Mestrado. PPGS, Fortaleza, 2004.

Porto Alegre, Sylvia. Mãos de Mestre: itinerários de arte e tradição. São Paulo: Maltese, 1994.

ReDFIELD, Robert. The Little Community as a Whole. In The Little Community and Peasant and Culture. Chicago: The University of Chicago Press, 1965, pp 1-16.

SAYAD, Abdelmalek. Uma Família Deslocada. In A Miséria do Mundo. Petrópolis, Vozes, 2001, pp 159-166.

VIVES, Vera de. A Beleza do Cotidiano. In O artesão tradicional e seu papel na sociedade contemporânea. Textos de Berta G. Ribeiro e outros. Rio de Janeiro, FUNARTE/ Instituto Nacional do Folclore. 1983. 253p.

XAVIER, Leandro Pinto. "Fazendo Arte: a relação entre o valor simbólico e o valor utilitário da cerâmica no Distrito de Icoaraci/PA". Lato \& Sensu, Belém, v-2, n-3, p. 23-29, jul, 2001.

Recebido em: 05/08/2013

Aprovado em: 28/08/2013 